\title{
COMPARISON OF OBSERVED AND MODELED ICE MOTION IN THE ARCTIC OCEAN
}

\author{
by \\ H. Jay Zwally \\ (Laboratory for Oceans, NASA/Goddard Space Flight Center, Greenbelt, MD 20771, U.S.A.)
}

and

John E. Walsh

(Department of Atmospheric Sciences, University of Illinois, Urbana, IL 61801, U.S.A.)

\begin{abstract}
Daily maps of multiyear ice concentration, derived from Nimbus-7 SMMR passive microwave data, are analyzed to obtain the displacement of the multiyear ice edge and information on the convergence/divergence within the pack. The dynamic-thermodynamic sea-ice model of Hibler (1979) is run with daily time steps and with forcing by the interannually varying fields of geostrophic wind and temperature-derived thermodynamic fluxes. Model-data comparisons are made for the net drift during the months of November through January of the 1978-79, 1979-80, and 1980-81 seasons, and for the shorter-term drift during a 52 day period. Both the model and the data-based drifts for the 25 November 1978 to 28 January 1979 period differ from the classical Beaufort-gyre pattern exhibited in the other two winters. For the 52 day period of NovemberDecember 1978, both the model and the data show an eastward drift followed by a westward drift of the ice edges in the Laptev Sea, and for the 25 November 1978 to 28 January 1979 period, a net westward drift of about $250 \mathrm{~km}$. Overall, the model and the data exhibit the same patterns of ice movement with marked month-to-month and large interannual variations in the drift. Good agreement is found in most regions of the central Arctic, but pronounced discrepancies occur near the edge of the total ice pack in the East Greenland Sea. During a short period of large changes in multiyear ice concentration in the central Arctic around 2 December 1980, the divergence implied by the changes in multiyear concentration is qualitatively compared with the divergence computed from the modeled velocity fields. Both the microwave data and the model results indicate similar temporal characteristics of pack-ice response during this major deformation event.
\end{abstract}

\section{INTRODUCTION}

Large-scale geophysical modeling requires effective use of commensurate data fields for initialization and verification. In the case of large-scale sea-ice modeling (e.g. Hibler 1979, 1980; Parkinson and Washington 1979), climatological data fields have been mostly used with few exceptions. This situation exists largely because only a few sea-ice parameters are observable on global scales with sufficient frequency. Furthermore, the observable parameters are mostly not the same as the ice parameters on which the models have been structured. The exception is sea-ice extent, which is usually defined as the $10-15 \%$ total ice-concentration boundary. Sea-ice extent has been well measured by satellites since 1973, and has been used for comparison with sea-ice models by several investigators (Hibler and Ackley 1983; Parkinson and Bindschadler 1984). Limited use has also been made of sea-ice concentration from passive microwave imaging for comparison with a similar model parameter, compactness (Hibler 1979; Parkinson 1983). Recently, observed atmospheric data over 25 years have been used to model the interannual fluctuations of the Arctic ice pack with particular attention to the ice-velocity fields (Hibler and Walsh 1982; Walsh and others 1985).

The modeled ice-velocity fields are highly variable on the short time-scales characteristic of synoptic weather systems and on interannual time-scales. Consequently, large-scale observational data sets on daily to interannual time-scales are essential for effective comparisons with the modeled parameters. Sea-ice thickness is a fundamental parameter describing the ice pack and has been a basic parameter in the formulation of sea-ice models (Thorndike and others 1975). However, there is no known technique for large-scale measurement of sea-ice thickness. Inferences on ice thicknessess from ice-type distributions have some potential utility, but it should be emphasized that direct large-scale measurement of sea-ice thickness is not a realistic possibility. Consequently, it is essential to examine the relationships among the parameters that are observable on large scales, which implies measurement by satellite remote sensing, and the parameters that are presently used (or could be used) in ice models.

Recent analysis of time series of multiyear ice-concentration fields derived from satellite passive microwave data has shown that the winter-time drift of the multiyear ice pack in the central Arctic and information on the convergence and divergence can be obtained. The principle, on which the derivation of drift and convergence/ divergence is based, is the approximate conservation of multiyear ice area during winter. Consequently, changes in multiyear concentration can be related to ice advection in places of large concentration gradients and to convergence and divergence within the ice pack. (Multiyear ice is defined in this study as ice that has survived one summer's melt season and includes second-year and older ice types.)

As discussed in the following sections, multiyear ice concentration is not directly a model parameter, but ice-velocity fields and, consequently, convergence and divergence fields are basic model outputs. The purpose of this paper is to examine the relationships between the modeled ice velocity and the drift and convergence/ divergence derived from the multiyear concentration maps. In particular, the compatibility of the fluctuations of the quantities deduced from the SMMR imagery and from a dynamic-thermodynamic sea-ice model is addressed. The emphasis is on time-scales ranging from several days to several months.

\section{SEA-ICE MODEL SUMMARY}

The ice model used here is based on the formulation of Hibler (1979). Modifications to the model thermodynamics have been described by Walsh and others (1985), who also described the domain, initialization, and other aspects of the multi-decadal simulations performed with the model. The essential features of the model are: (1) a momentum balance based on geostrophically derived air 
and water stresses, Coriolis force, ocean tilt, internal ice stress, and inertial terms; (2) an ice rheology based on a viscous-plastic constitutive law and an ice-strength parameter, P*; (3) an ice-thickness distribution characterized by the compactness and the mean ice thickness averaged over an entire grid cell; and (4) a thermodynamic code in which vertical growth rates are estimated from heat-budget computations at the top and bottom surfaces of the ice and from heat stored in a motionless oceanic boundary layer. In order to incorporate the strong thickness dependence of ice-growth rates, the thermodynamic computations utilize a seven-level distribution of thicknessess equally spaced between 0 and $2 h_{m}$, where $h_{m}$ is the mean thickness of the ice in a grid cell. Each of these thicknesses is assumed to represent one-seventh of the ice-covered area of each grid cell.

The thickness distribution described above represents merely a first-order attempt to include a range of thicknessess in the model thermodynamics. In reality, a considerable part of the central Arctic contains deformed ice, some of which will exceed $2 \mathrm{~h}_{\mathrm{m}}$ in thickness. Perhaps more importantly, the mix of first-year and multiyear ice may favor a tendency toward non-linear thickness distributions with peaks corresponding to new, second-year, and/or older multiyear ice (e.g. Williams and others 1975, fig.9). The distinction between first-year and multiyear ice, while readily apparent in the SMMR imagery, is lost in the model formulation because of the oversimplification of the thickness distribution.

The mean thickness, $h_{m}$, and the compactness, A, of the ice in a grid cell change over time through the processes of advection, convergence/divergence, and growth/ melt (Hibler 1979):

$\frac{\partial h_{m}}{\partial t}=-\frac{\partial\left(\mathrm{uh}_{\mathrm{m}}\right)}{\partial \mathrm{x}}-\frac{\partial\left(\mathrm{vh}_{\mathrm{m}}\right)}{\partial \mathrm{y}}+\mathrm{S}_{\mathrm{h}}+$ diffusion

$\frac{\partial A}{\partial t}=\frac{\partial(\mathrm{uA})}{\partial \mathrm{x}}-\frac{\partial(\mathrm{vA})}{\partial \mathrm{y}}+\mathrm{S}_{\mathrm{A}}+$ diffusion

where $\mathrm{u}$ and $\mathrm{v}$ are the ice-velocity components in a Cartesian $(x, y)$ coordinate system. The diffusion terms in Equations (1) and (2) are only included for numerical stability and are small. $S_{h}$ and $S_{A}$ represent the changes due to growth and melt:

$\mathrm{S}_{\mathrm{h}}=\sum_{\mathrm{i}=1}^{7} \frac{\mathrm{A}}{7} \mathrm{f}\left(\mathrm{h}_{\mathrm{i}}\right)+(1-\mathrm{A}) \mathrm{f}(0)$

$S_{A}=\left\{\begin{array}{cl}(1-A) \frac{f(0)}{h_{0}} & \text { if } f(0)>0 \\ 0 & \text { if } f(0)<0\end{array}\right\}+\left\{\begin{array}{cc}0 & \text { if } S_{h}>0 \\ \frac{A}{2 h_{m}} S_{h} & \text { if } S_{h}<0\end{array}\right\}$

where $f\left(h_{i}\right)$ is the growth rate of ice of thickness $h_{i}$ and $\mathrm{h}_{\mathrm{O}}=0.5 \mathrm{~m}$ is a prescribed upper bound on the thickness of "thin ice". The term $S_{h}$ in Equation (3) indicates simply that the net growth rate is a concentration-weighted mean of the growth rates of the ice of different thicknesses (including growth over open water). The above equations are subject to the constraint that $\mathrm{A} \leqslant 1$, which effectively introduces a "sink term" when $\mathrm{A}=1$ under convergent ice motion. This sink term allows $h_{m}$ to increase while A remains equal to 1.0 , thus permitting some thickness build-up under condition of $100 \%$ ice cover. The $\mathrm{S}_{\mathrm{A}}$ term in Equation (4) allows for the rapid decay of open water $(1-A)$ under freezing conditions, as well as for the decrease of A under melting conditions $\left(S_{A} \leqslant 0\right)$. Under the assumption of a linear distribution of ice thickness, the ice of thickness less than $\mathrm{S}_{\mathrm{h}} \Delta \mathrm{t}$ will melt and form open water over time $\Delta \mathrm{t}$; this ice covers an areal fraction equal to $\mathrm{S}_{\mathrm{h}} \Delta \mathrm{tA} / 2 \mathrm{~h}$, which leads to the second term in Equation (4). This term does not represent lateral melt but rather the melt of the thinnest ice within an assumed thickness distribution.

The growth rates $f\left(h_{i}\right)$ are evaluated from an energy-balance computation including the major thermodynamic fluxes at the top and bottom ice surfaces (e.g. radiative fluxes, sensible and latent heat transfer, conduction). The formulation of these terms is essentially the same as that used by Parkinson and Washington (1979), although the treatment here partitions the snow cover as well as the sea ice into seven thickness categories (Walsh and others 1985).

As noted earlier, the linear distribution assumed for the ice thickness is somewhat unrealistic. An associated problem in the model formulation is the temporal dependence of the thickness-category delimiters. Because these delimiters are equally spaced between 0 and $2 h_{m}$, the delimiters change as the ice thickness changes. It is therefore not possible in the model results to distinguish multiyear and new ice by "tagging" segments of ice cover through periods of growth or melt. Because the simplified treatment of ice thickness in the model thus precludes a direct comparison with the SMMR imagery, the fields of model ice drift and deformation are used for comparison with the SMMR data in the following sections.

\section{MULTIYEAR CONCENTRATON DATA}

Since 1978, 6 day average maps of multiyear concentration, $\mathrm{C}_{\mathrm{m}}$, have been made by the Nimbus project from the multi-frequency and dual-polarization passive microwave imaging data obtained by the SMMR (Scanning Multichannel Microwave Radiometer) on the Nimbus-7 satellite (e.g. Cavalieri and others 1984). Using the hypothesis that multiyear ice area should be approximately conserved during winter, except for small reductions due to ridging of multiyear ice, Zwally and Cavalieri (paper in preparation) showed that the total area of the observed multiyear ice, (integral $C_{m}(x, y, t)$ ), over regional-scale boxes $(\sim 1500 \mathrm{~km} \times 1500 \mathrm{~km})$ is approximately conserved from November through April, with short-term variations of about $8 \%$ (one sigma) due to advection and undetermined measurement errors.

As discussed by Zwally and Cavalieri (paper in preparation), $C_{m}(x, y, t)$ follows the continuity equation,

$\frac{\partial \mathrm{C}_{\mathrm{m}}}{\partial \mathrm{t}}=-\operatorname{div} \cdot\left(\mathrm{C}_{\mathrm{m}} \mathrm{V}\right)+\mathrm{S}_{\mathrm{cm}}$

where $\mathrm{V}$ is the ice volocity and $\mathrm{S}_{\mathrm{cm}}$ is the multiyear source term that is approximately zero during winter. Equation (5) formally relates changes in $\mathrm{C}_{\mathrm{m}}$ to divergence of the velocity field and advection. Therefore, the time dependence of $C_{m}$ can be used to study deformation of the ice pack. In contrast to $C_{m}(x, y, t)$, the total concentration $C_{t}(x, y, t)$ also decreases during divergence, for example, but under conditions of ice growth in open leads and polynyas $C_{t}$ quickly increases as new ice is formed. During convergence, it is presumed that most of the ridging occurs in the weaker new and first-year ice

Locations of large gradients of $C_{m}$, such as near the edge of the multiyear ice pack, provide markers for studying the large-scale drift of the ice pack, using the following relation between the velocity, $W_{x}$, of a constant $\mathrm{C}_{\mathrm{m}}$ line in the $\mathrm{x}$-direction, for example, and the actual ice velocity u:

$\mathrm{w}_{\mathrm{x}}=\frac{-\partial \mathrm{C}_{\mathrm{m}} / \partial \mathrm{t}}{\partial \mathrm{C}_{\mathrm{m}} / \partial \mathrm{x}}=\mathrm{u}+\frac{\mathrm{C}_{\mathrm{m}} \text { div. } \mathrm{V}}{\partial \mathrm{C}_{\mathrm{m}} / \partial \mathrm{x}}$.

The second term in Equation (6) tends to be negligible at the edge of the multiyear ice pack, as shown by Zwally and Cavalieri (paper in preparation), where the edge is defined by the $C_{m}=20 \%$ line. Together, Equations (5) and (6) provide quantitative relations between changes in $C_{m}$ and drift, and convergence/divergence. A descriptive relationship between motion of the observed multiyear ice pack and surface winds deduced from surface-pressure maps has been illustrated by Zwally and Cavalieri. Here, the sea-ice model is used to relate the observed atmospheric forcing to the observed changes in sea-ice distribution.

4. COMPARISON OF SIMULATED AND SMMR-DERIVED ICE DRIFT

The sea-ice drift obtained from the model results and the SMMR imagery are compared over three time-scales. First, the interannual variability of seasonal means is 
NOV. 25
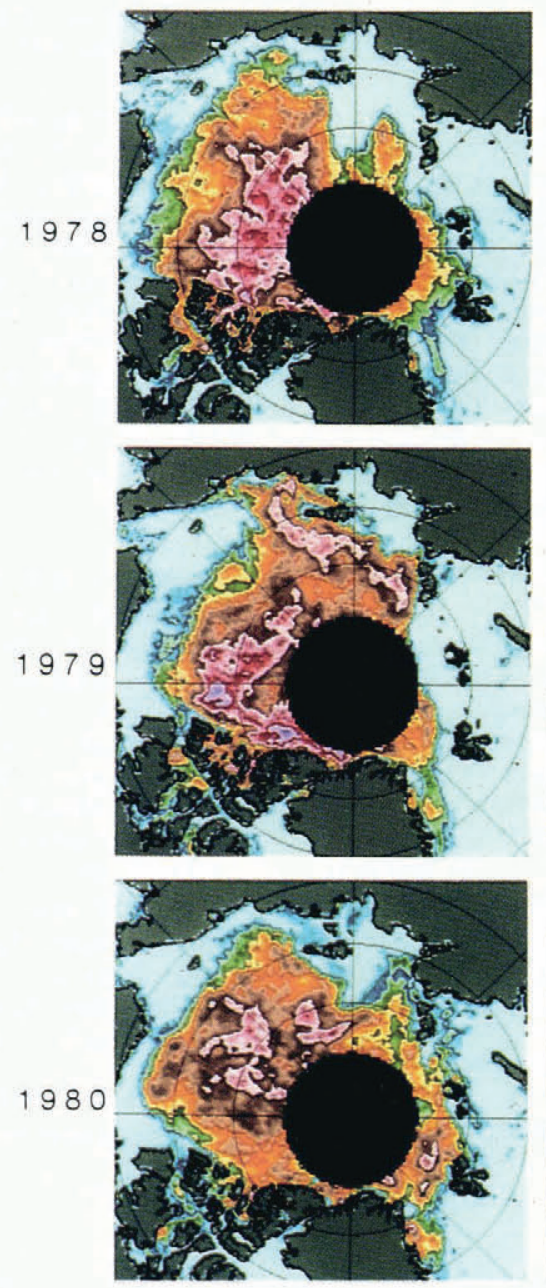

JAN. 30
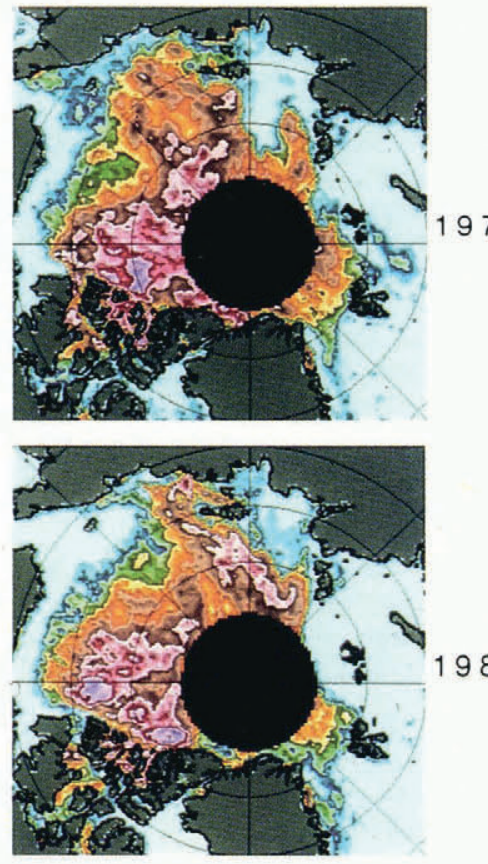

1980

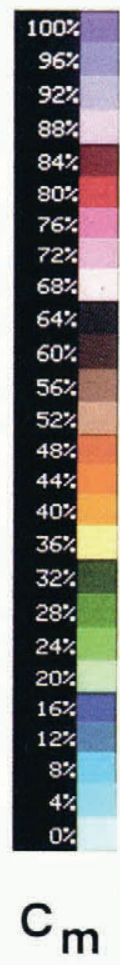

Fig.1. SMMR images of multiyear sea-ice concentration for 25 November and 30 January of 1978-

79, 1979-80, and 1980-81.

examined for a set of three successive winters, 1978-79 through 1980-81. Secondly, the two sets of drift information are used in a comparison of intra-seasonal variations during a period characterized by two distinctive regimes of ice drift. Finally, the comparison focuses on the short-term fluctuation associated with an extreme synoptic event that appears to have produced a relatively long-lasting signal in the SMMR imagery for the winter of 1980-81. Comparisons with fluctuations of the analyzed pressure fields for these periods are also noted in this section. In the following section, the results of the December 1980 event are analyzed in terms of a derived quantity, the velocity divergence.

\section{a. Interannual variability of seasonal mean drift}

As an illustration of the interannual variability of multiyear sea-ice coverage in the Arctic, Fig.1 shows the multiyear ice concentrations in late November and late January of the winters of 1978-79 through 1980-81. Large interannual fluctuations of the ice edge are apparent in the Laptev, East Siberian, and Chukchi Seas. The multiyear concentrations within the pack also vary considerably from year to year (e.g. January 1979 vs January 1981). A tendency for the concentration anomalies to be of opposite sign in different sectors of the Arctic is apparent. For example, the multiyear ice concentration is noticeably lighter near long. $120-150^{\circ} \mathrm{E}$. and heavier near long. $150-180^{\circ} \mathrm{E}$. in 1981 than in 1980. Seasonal shifts in the position of the multiyear ice edge are also apparent in Fig.1, as illustrated by the westward shift of the multiyear ice edge in the Laptev Sea between late November 1978 and late January 1979. The seasonal advances and retreats of the multiyear edge are summarized for each year in Fig.2. Displacements of $100-200 \mathrm{~km}$ during the 10 week period are not uncommon, and the tendency for corresponding displacements of opposite sign in adjacent sectors is again apparent.

Fig.3 shows the model-simulated drift vectors for the periods corresponding to the SMMR-deduced drift in Fig.2. While an anticyclonic gyre dominates the North American sector of the central Arctic in 1979-80 and 1980-81, the trans-polar drift stream dominates the entire Arctic Basin in 1978-79. The contrasting flow patterns result in a flux of ice toward the Laptev Sea in 1978-79, modest outflow from the Laptev Sea in 1979-80, and strong outflow in 1980-81. These year-to-year differences are apparent in the areas of multiyear advance and retreat in Fig.2, which also supports the interannual variability of the model's meridional flow component superimposed on the westward drift north of Alaska and the Bering Strait (e.g. retreat in 1978-79, advance in 1980-81, and the gyre-induced juxtaposition of advance and retreat in 1979-80). The largest discrepancy between the model- and SMMR-derived drift is in the East Greenland Sea, especially in 1980-81, when the model indicates outflow rather than the retreat implied by the SMMR data. The model results have been shown elsewhere to be deficient in the North Atlantic waters because of the absence of oceanic coupling (Walsh and others 1985). Since ambiguities in the microwave signature are also known to occur in this region, there is little reason to expect close agreement there.

\section{b. Intra-seasonal variability, late 1978, Siberian sector}

By the procedure used to deduce the ice-edge motion depicted in Fig.2, the SMMR-derived multiyear ice concentrations were used to deduce the short-term 


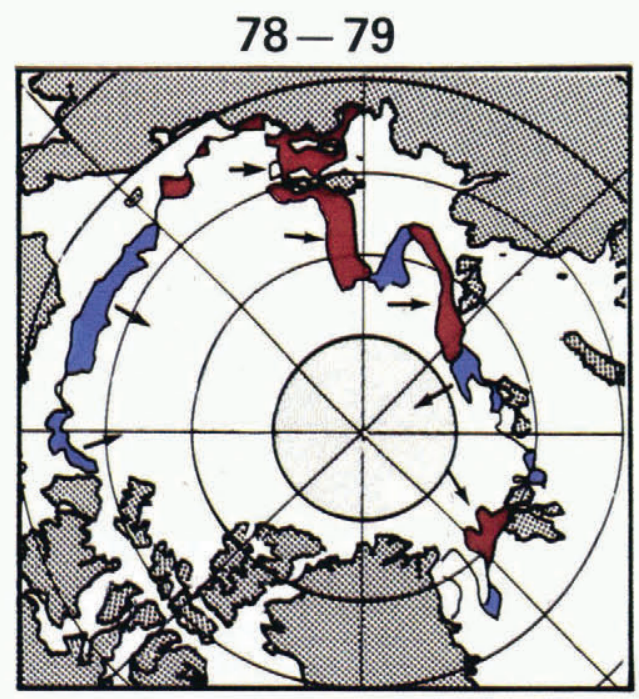

$79-80$

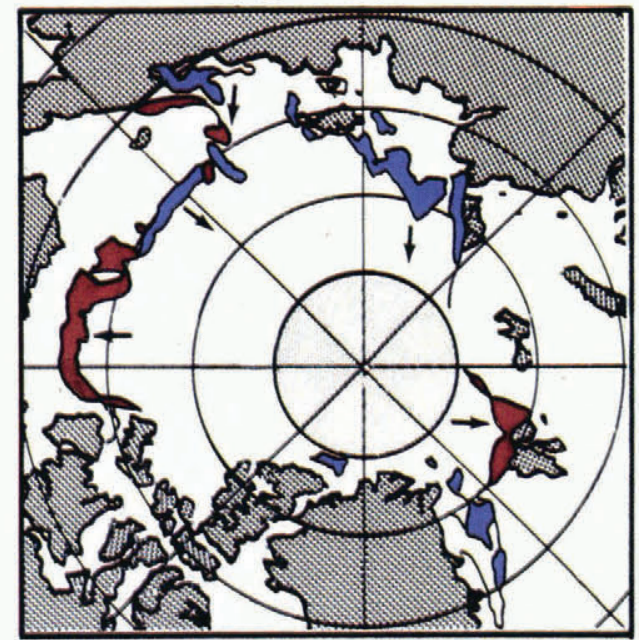

\section{DRIFT OF} MULTIYEAR ICE EDGE

\author{
NOV 25 TO JAN 30
}

Fig.2. Motion of the multiyear ice edge derived from the SMMR images of Fig.1. Areas of ice advance and retreat are indicated by red and blue, respectively.

movement of the ice edge near long. $140^{\circ} \mathrm{E}$. (shown in Fig.1, 25 November 1978) during the period 1 November to 23 December 1978. Inspection of the images had shown that the first part of this period was characterized by generally eastward motion of the ice edge, while the second part was characterized by generally westward motion. Fig.4 shows clearly the contrast in the longitudinal component of the drift of this ice edge prior and subsequent to 23 November. The model-simulated drift for the two sub-periods is shown in Fig.5. The flux of ice across the pole during the first sub-period contrasts with the absence of trans-polar drift in the second sub-period. The dramatic reversal of the simulated drift is especially apparent in the Laptev and East Siberian Seas. The simulated ice thickness averaged over the Laptev Sea is $0.8 \mathrm{~m}$ at the end of October, $0.9 \mathrm{~m}$ at the end of November, and $1.3 \mathrm{~m}$ at the end of December. The more rapid increase in simulated thickness during December is caused by the large ice motion toward the coast.

Support for the hypothesis that wind forcing is primarily responsible for the reversal is provided by the corresponding fields of sea-level pressure (Fig.6). The circulation during the first sub-period is dominated by south-westward flow around a strong Barents Sea cyclone, which is essentially absent in the second sub-period. Southeastward flow during the latter sub-period occurs between a weak ridge near the North Pole and a Bering Sea cyclone displaced about $500 \mathrm{~km}$ north-west of its normal position. The larger anomalies relative to the climatological mean circulation occurred during the first sub-period, when departures from normal pressure were as large as $20 \mathrm{mbar}$ in the Barents Sea.

\section{c. Decrease of multiyear coverage, December 1980}

The multiyear ice-concentration fields for 30 November (day 335) and 2 December (day 337) 1980 (Fig.7a and b) indicate a rapid reduction of multiyear ice concentration in the pack ice north of Alaska. Decreases of as much as $30-40 \%$ occurred during this period in the region between the Chukchi Sea and the North Pole (Fig.7c). Multiyear concentrations of less than $40 \%$ then persisted throughout much of the following 2 months, as indicated by the concentration field for 31 January 1981 (see Fig.1). These concentration changes correspond to reductions in total multiyear ice area of more than $50 \%$ over scales of several hundred kilometers. During this interval, the observed total multiyear ice area (integral of $C_{m}$ ) over a regional-scale box enclosing the low-concentration area showed a temporary decrease of about $15 \%$, which is typical of the maximum variations of this quantity about a mean value during the winter season and considered to be at least partly due to ice advection through the box boundaries. Specifically, the multiyear ice area in the box (lat. $67.6^{\circ} \mathrm{N}$., long. $152.5^{\circ} \mathrm{W}$; lat. $81.1^{\circ} \mathrm{N}$., long. $185.2^{\circ} \mathrm{W}$; ; lat. $67.8^{\circ} \mathrm{N}$., long. $118.9^{\circ} \mathrm{W}$.; lat. $81.5^{\circ} \mathrm{N}$., long. $87.3^{\circ} \mathrm{W}$.) enclosing the Beaufort Sea and northward varied from 8.5 to 6.9 to 7.4 to $8.8 \times 10^{5} \mathrm{~km}^{2}$ on days $335,337,339$, and 365 . The corresponding values of total multiyear ice area in the Chukchi and East Siberian Seas box (lat. $61.9^{\circ} \mathrm{N}$., long. $176.0^{\circ} \mathrm{W}$.; lat. $70.6^{\circ} \mathrm{N}$., long. $208.1^{\circ} \mathrm{W}$.; lat. $67.6^{\circ} \mathrm{N}$., long. $152.5^{\circ} \mathrm{W}$.; lat. $81.1^{\circ} \mathrm{N}$., long. $185.2^{\circ} \mathrm{W}$.) are $4.6,4.5,4.4$ to $4.8 \times 10^{5} \mathrm{~km}^{2}$ on days $335,337,339$, and 365 .

The low concentrations around lat. $80^{\circ} \mathrm{N}$. and long. 
$165^{\circ} \mathrm{W}$. appear to be consequences of the strong deformation associated with a major cyclonic system that moved northward into the Arctic on 1-2 December. The intensity of the cyclonic system is apparent in Fig.8, which is an analysis of sea-level pressure observations from the network of Arctic drifting buoys (Thorndike and Colony 1981), one of which reported a pressure of 984 mbar near the analyzed cyclone center in Fig.8. The gradient of sea-level pressure in the Alaskan Arctic is stronger during this event than in any other December analysis of the 5 year record of buoyderived analyses. While the cyclonic system weakened and migrated northward after 2 December, it remained the

\section{8-1979 (NOV.25-JAN.28)}

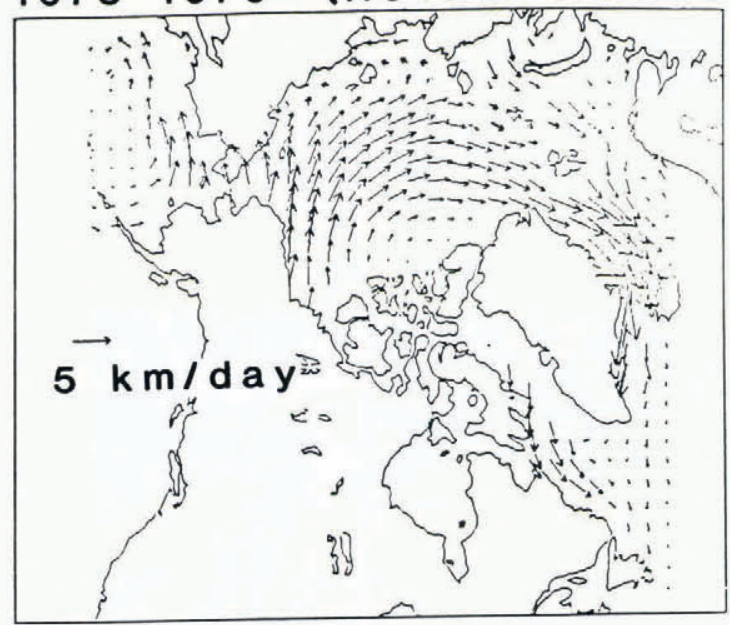

1979-1980 (NOV.25-JAN.28)

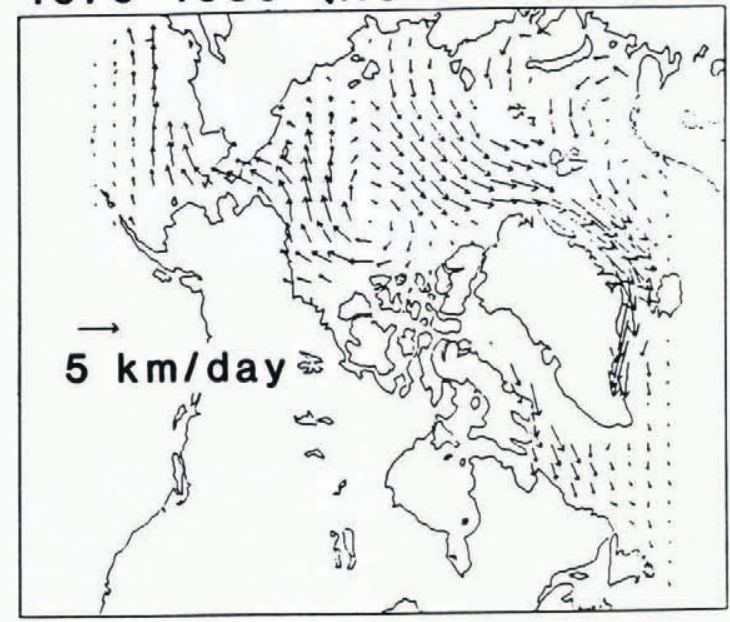

1980-1981 (NOV.25-JAN.28)

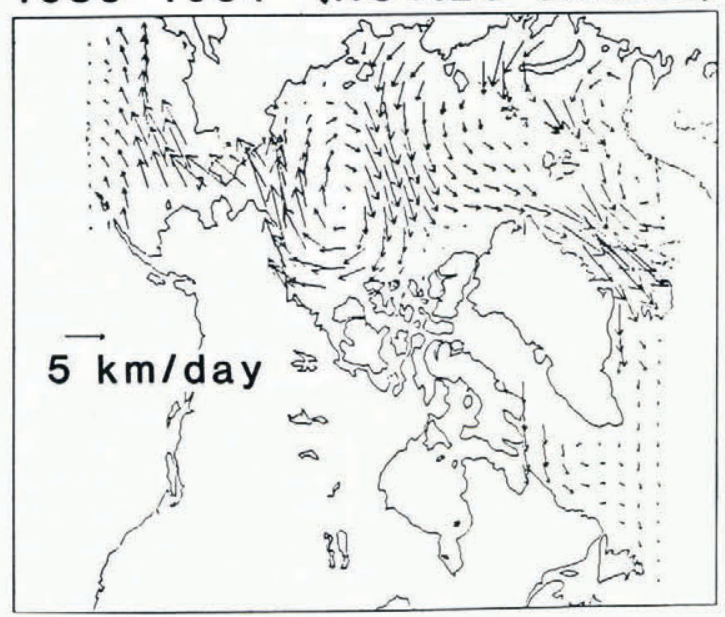

SIMULATED DRIFT VECTORS

Fig.3. Simulated drift vectors for 25 November-30 January of $1978-79,1979-80$, and $1980-81$.

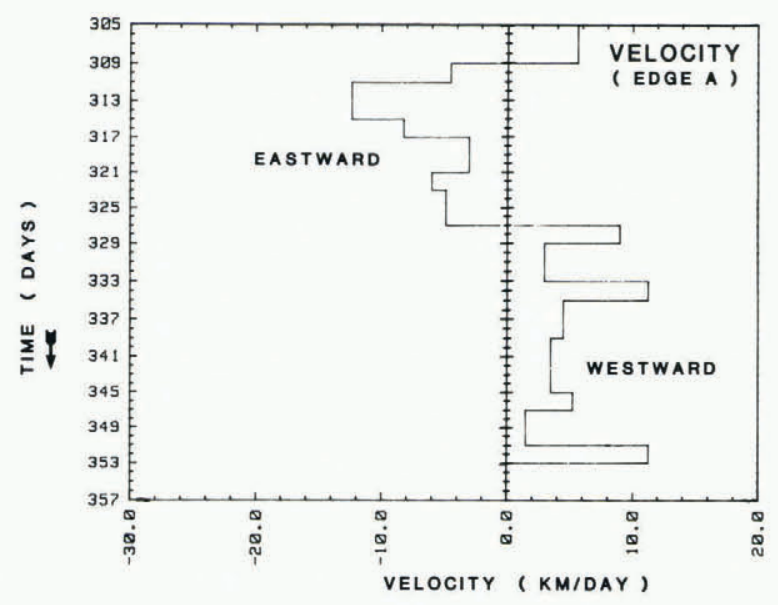

Fig.4. East-west component of motion of multiyear ice edge between lat. $77^{\circ}$ and $82^{\circ} \mathrm{N}$. at approximately long. $140^{\circ} \mathrm{E}$. in the Laptev Sea from 1 November to 23 December 1978 , as derived from displacement of the SMMR $20 \%$ multiyear concentration line.

OCT. 29 - NOV. 25,1978

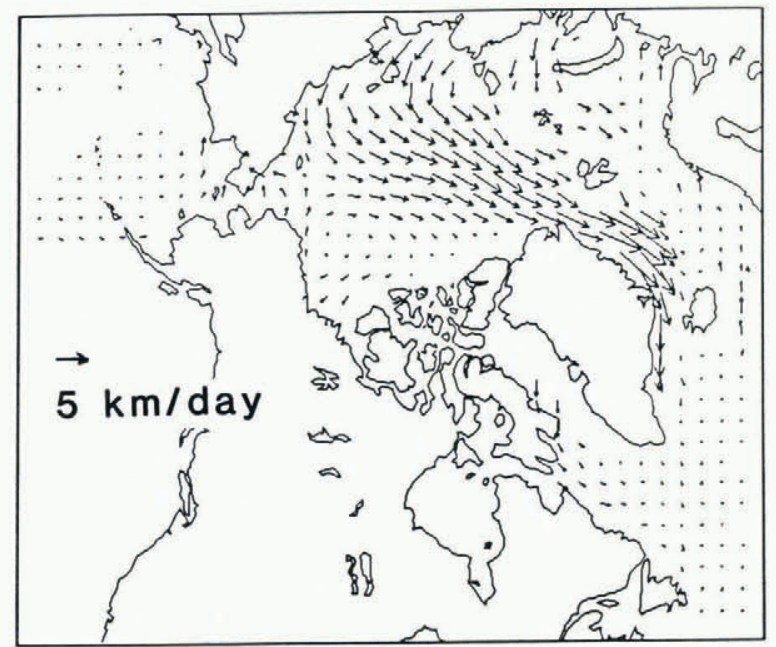

NOV. 26 - DEC. 23,1978

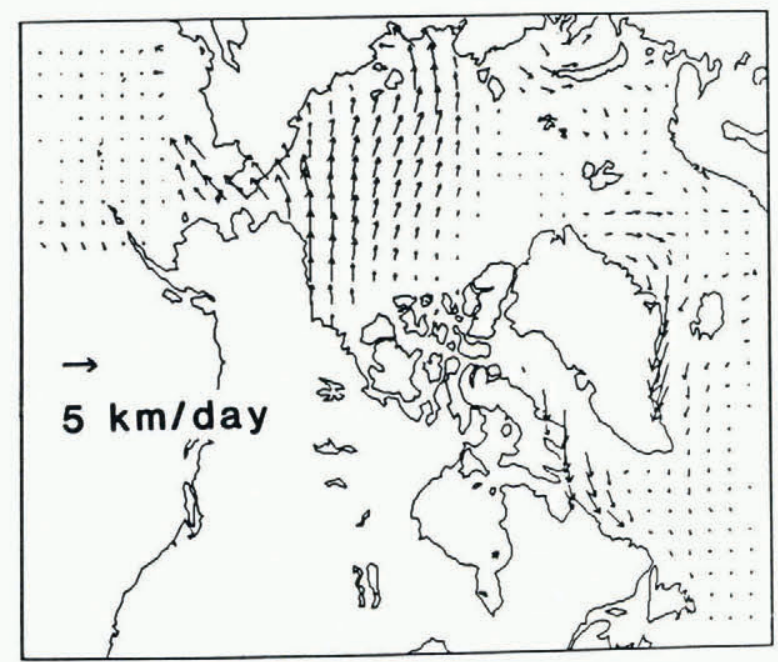

\section{SIMULATED DRIFT VECTORS}

Fig.5. Simulated drift vectors for 29 October-25 November 1978 (upper) and 26 November-23 December 1978 (lower) showing correlation with observed motion (Fig. 4). 
dominant feature of the Arctic circulation for the subsequent 3-4 days.

Fig.9 shows the simulated drift vectors for the period of 2-8 December 1980. Strong cyclonic drift opposite to the climatological mean drift for early December dominates the Arctic Basin. The apparent divergence of the drift vectors near the cyclone center is consistent with the view that sea ice generally drifts at a slight angle to the right of the surface wind (Zubov 1945). The angular deviation of $5-6^{\circ}$ found by Thorndike and Colony (1982) for the winter season is quite similar to the corresponding deflection from the geostrophic wind in the model drift (Walsh and others 1985). The apparent divergence in Fig.9 is clearly consistent with the decrease of ice concentration in the SMMR-derived concentrations of Fig.8. The fact that the reduced concentrations persist through January suggests that major synpotic events can have long-lived effects on the characteristics of sea ice in the central Arctic. This "irreversibility" of the consequences of deformation events requires further investigation in other years and seasons in order to determine the generality of such impacts.

\section{DIVERGENCE COMPUTATIONS}

While velocity fields such as those discussed in section 4 provide information pertinent to large-scale transport, the spatial gradients of the velocities are more relevant to some fundamental aspects of sea-ice behavior. As components of the strain-rate tensor, the velocity gradients are measures of the deformation that dictates changes in quantities of major importance to the dynamics and thermodynamics of sea ice: the areal fraction of open water, the internal ice stress, and the ice-thickness distribution. In this section, some of the temporal and spatial aspects of the divergence associated with the December 1980 event discussed in section 4 are evaluated.

Fig.10 shows the time series of the daily model divergence averaged over the nine grid cells centered on lat. $80^{\circ} \mathrm{N}$., long. $165^{\circ} \mathrm{W}$. Fluctuations characteristic of the passage of transient synoptic systems occur throughout much of November and December 1980. The largest value of either sign occurs on 2 December, when the cyclonic system discussed earlier migrated over the nine-point area. Interestingly, the effect of this system appears as a "spike" confined to about 3 days. The short-term nature of the divergence event is supported by the SMMR-derived changes of multiyear ice concentration along a transect from the north-western Canadian coast (lat. $79.4^{\circ} \mathrm{N}$, long. $104.3^{\circ} \mathrm{W}$.) to the New Siberian Islands (lat. $76.1^{\circ} \mathrm{N}$., long. $142.3^{\circ} \mathrm{E}$.). Fig. 11 shows that the decreases of concentration between 30 November and 2 December are large $(20-40 \%$ in the central Arctic), but that the antecedent and subsequent 2 day periods show little or no evidence of such a decrease. These results support the contention made earlier that the persistent area of first-year ice during the 1980-81 winter may be attributed largely to a strong but short-lived deformation event.

The short-term forcing of this event must also be viewed in the context of the large-scale distribution of multiyear ice. The SMMR images of Fig.1 show that 1980 is characterized by generally lower concentrations of multiyear ice in the Alaskan sector during late November 1980 than at the corresponding time in 1978 and 1979. The contrast is especially apparent near the Canadian Archipelago, where the multiyear concentrations are $70-80 \%$ in the 1978 and 1979 images, but only $40-60 \%$ in the 1980 image. Moreover, the total ice concentrations of $~ 80 \%$ depicted for this region during September 1980 in the weekly ice analyses of the US Navy/NOAA Joint Ice Center were less than normal, while the model-derived concentrations of $80-90 \%$ for this period were also less than the 30 year September mean of the model results (although several other years had similar concentrations in September) The pack ice in the Alaskan part of the Arctic Basin may thus have been predisposed to a major deformation in response to an intense synoptic system. It is therefore quite possible that the pre-existing state of the pack, as well as the intensity of a particular synoptic system, contributed to the large and rapid decrease of multiyear concentration in December 1980.
OCT. 29 - NOV. 25, 1978

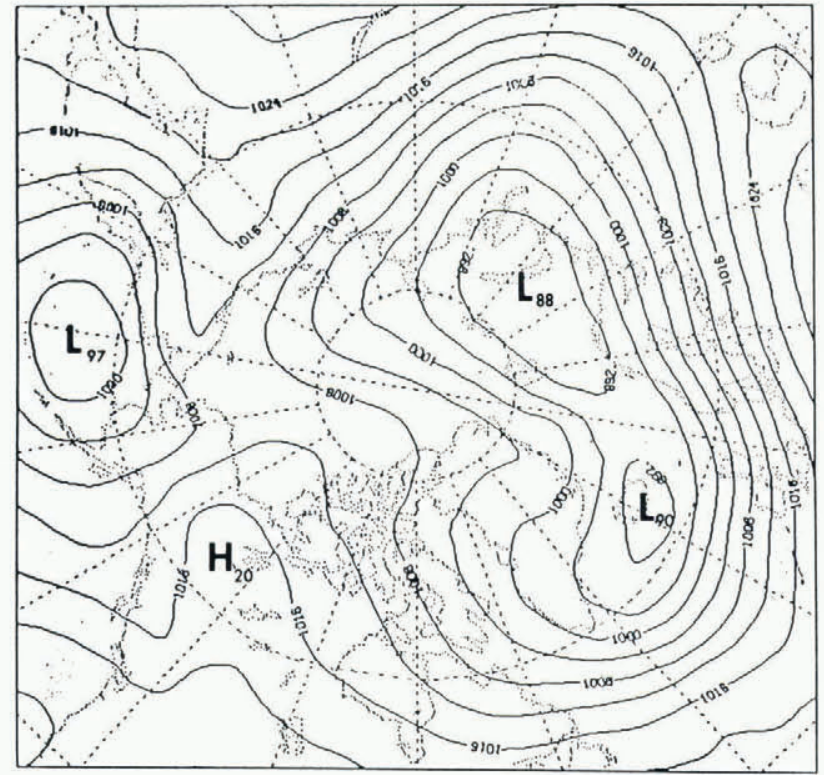

NOV. 26 - DEC. 23,1978

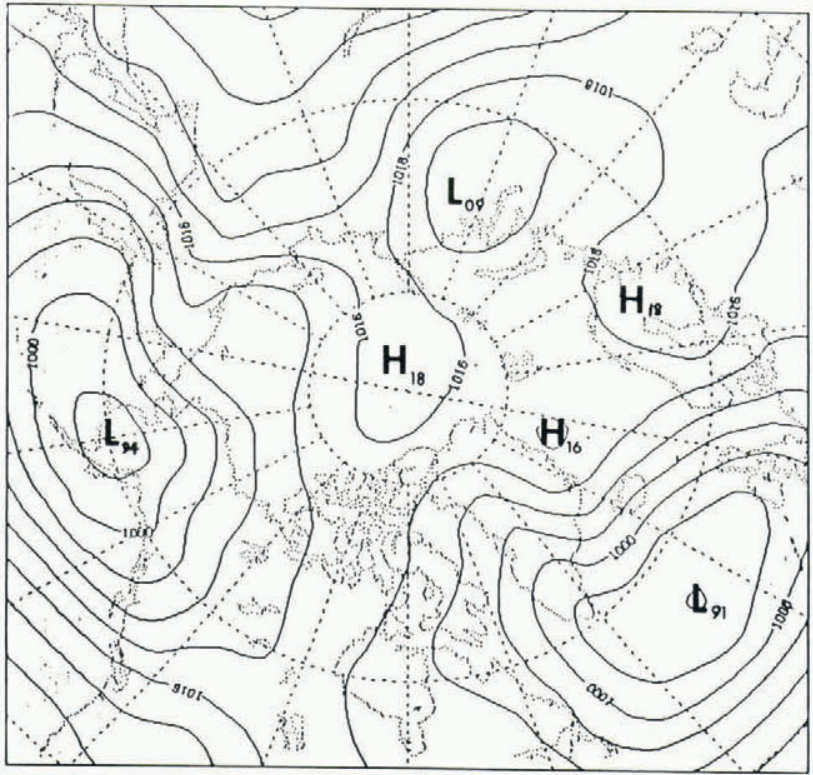

\section{SURFACE PRESSURE}

Fig.6. Fields of sea-level pressure averaged over the periods of ice drift shown in Fig.5.

The model-generated fields of divergence during the critical period of the deformation event are also examined on a daily basis for the first 2 weeks of December 1980 In agreement with the inference made visually from Fig.10, the simulated divergence is strongest in the immediate vicinity of the low-pressure center. The area of strongest divergence indeed migrated with the pressure center in the model simulation. It should be noted, however, that the model simulation was forced by gridded pressure analyses produced by the US Navy. The central pressure of the Arctic cyclone in the US Navy analysis for 2 December was 992 mbar (see Fig.8). The cyclonic circulation and associated ice divergence are thus likely to have been weaker in the present model simulation than if the same quantities had been computed from a more accurate analysis of sea-level pressure. 

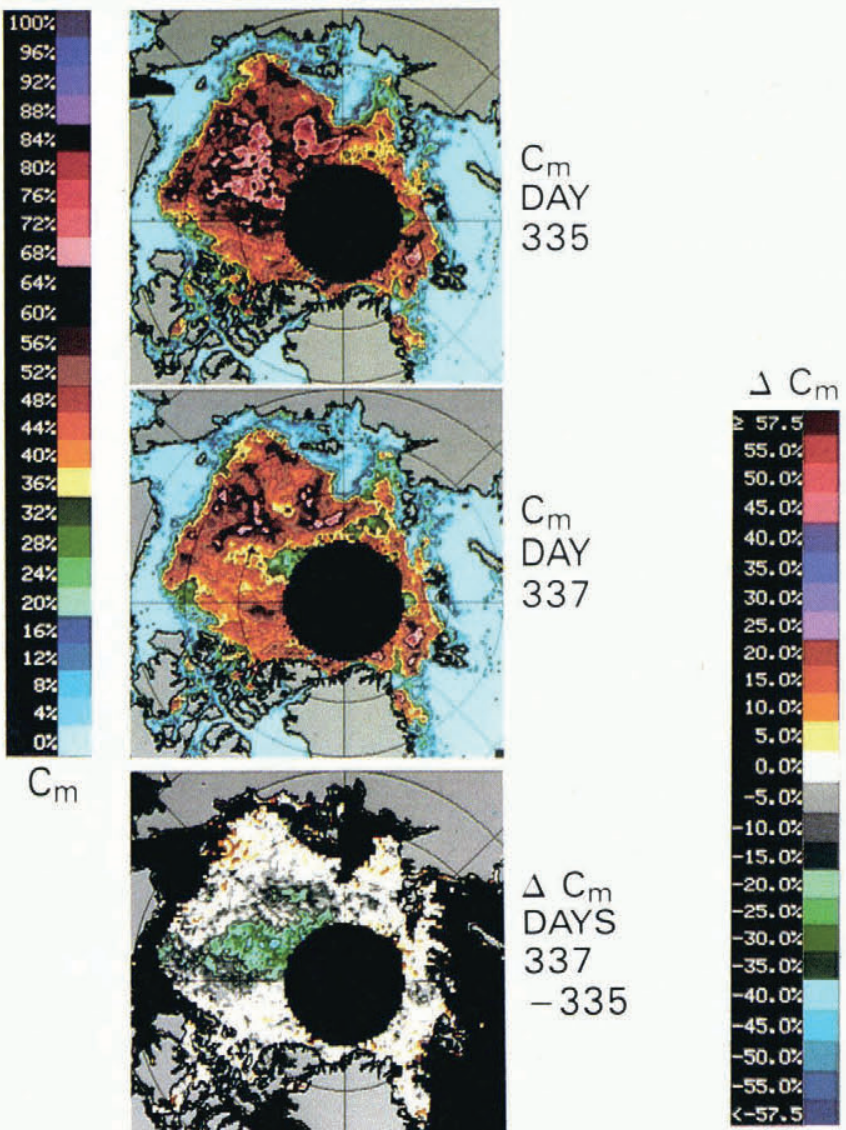

\section{SHORT-TERM MULTIYEAR CONCENTRATION CHANGES}

Fig.7. SMMR images of multiyear sea-ice concentration for 30 November (day 335, top) and 2 December (day 337, center) 1980. Field of change of multiyear concentration between 30 November and 2 December is shown at bottom.

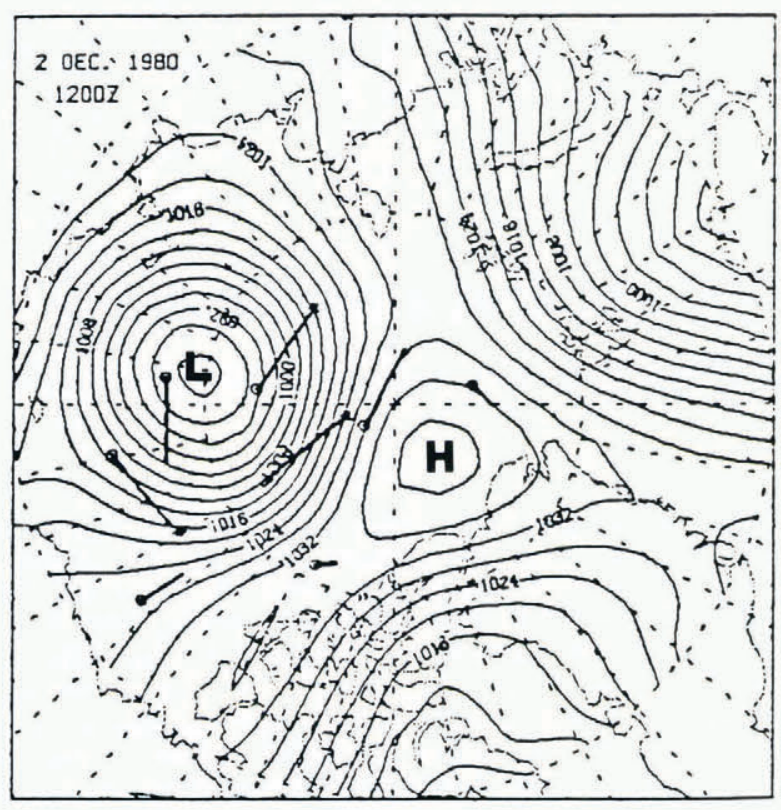

\section{SURFACE PRESSURE/BUOY DRIFT}

Fig.8. Sea-level pressure analysis for $12.00 \mathrm{Z} 2$ December 1980. Positions of Arctic buoys are shown by open circles, direction of buoy drift by linear segments (from Thorndike and Colony 1981).

\section{CONCLUSIONS}

The comparisons presented here show that the sea-ice velocity fluctuations deduced from SMMR data and from a dynamic-thermodynamic sea-ice model are generally compatible over the daily to seasonal time-scales. Several conclusions are drawn from the results in sections 4 and 5 .

(1) Daily, monthly, and even seasonally averaged fields of sea-ice motion are highly variable, and departures from the climatological "normal" field can dominate the mean patterns for periods of several days to several months. Thus, the field of motion for a particular month or season cannot be assumed to be representative of the long-term mean for the corresponding month or season.

(2) Because the variable air stress is the primary determinant of the model's drift fluctuations, which are generally consistent with the data-derived drift fluctuations, the variability examined here is attributed primarily to the fluctuations of the geostrophic wind or sea-level pressure. This conclusion applies to the daily to seasonal time-scales, and is not incompatible with the notion that oceanic variability may account for larger parts of the drift variability on time-scales longer than the monthly or seasonal (Thorndike and Colony 1982).

(3) Major synoptic events can have long-lived impacts on the concentration of multiyear ice in the central Arctic. The model-derived velocity divergence supports the inference from the SMMR data that the large decrease of multiyear ice concentration in December 1980 was limited to a period 
DEC. $2-8(337-343), 1980$

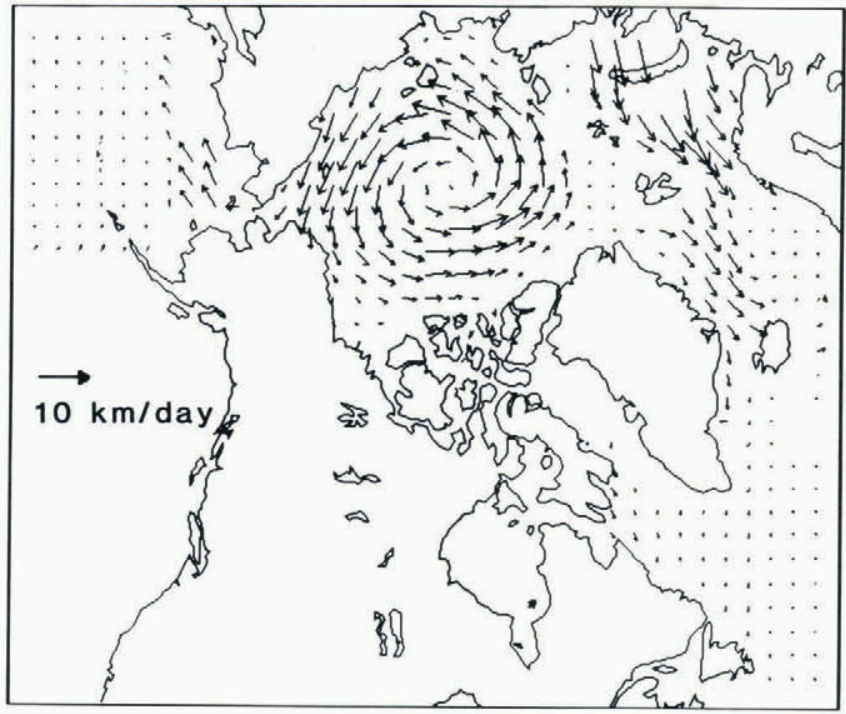

\section{SIMULATED DRIFT VECTORS}

Fig.9. Simulated drift vectors for 2-8 December 1980.

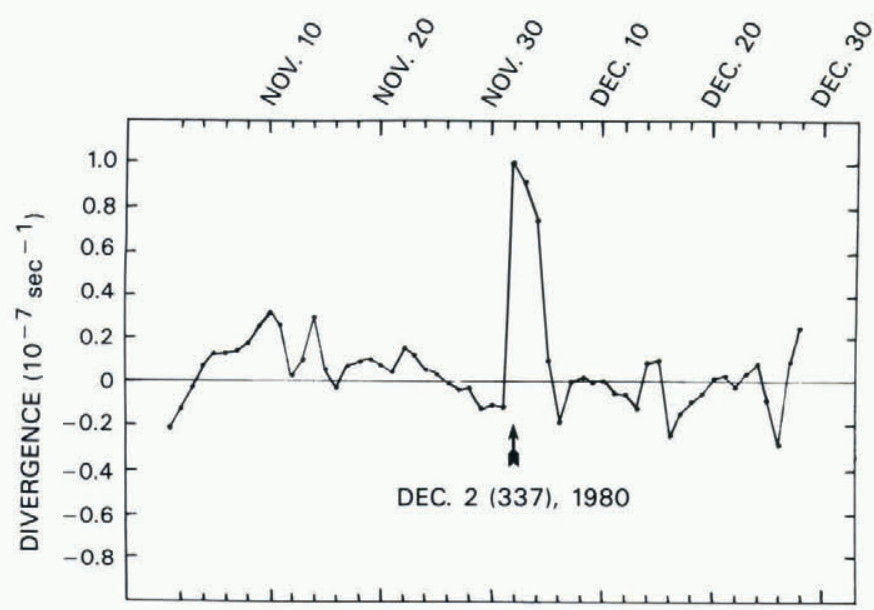

\section{SIMULATED DIVERGENCE AROUND $80^{\circ} \mathrm{N}, 165^{\circ} \mathrm{W}$}

Fig.10. Daily values of divergence of ice-model drift vectors for 1 November-30 December 1980. Divergences are averages over $666 \mathrm{~km}$ square (nine grid cells) centered at lat. $80^{\circ} \mathrm{N}$., long. $165^{\circ} \mathrm{W}$.

of 1-3 days, although the resulting low concentrations were apparent in the SMMR imagery for the next several months. The role of the large-scale state of the ice prior to the deformation event remains to be clarified.

(4) In view of the compatibility of the SMMR- and model-derived fields of ice divergence, it appears that the SMMR data represent an excellent tool for studies of the mass balance of Arctic pack ice. Work described by Zwally and Cavalieri (paper in preparation) has shown that the total areal coverage of multiyear ice is quasi-conservative during the winter months, implying that estimates of regional divergence of the multiyear ice can provide a measure of the area of new ice formation and growth within the pack during winter. Because the vast majority of ice growth takes place in areas of open water or young ice, the SMMR data may provide valuable input to assessments of a crucial component of the mass balance. Estimates of the seasonal and interannual variability of the areas susceptible to new ice growth can be used in assessing the validity of largescale ice models, as well as in assessing the variability of

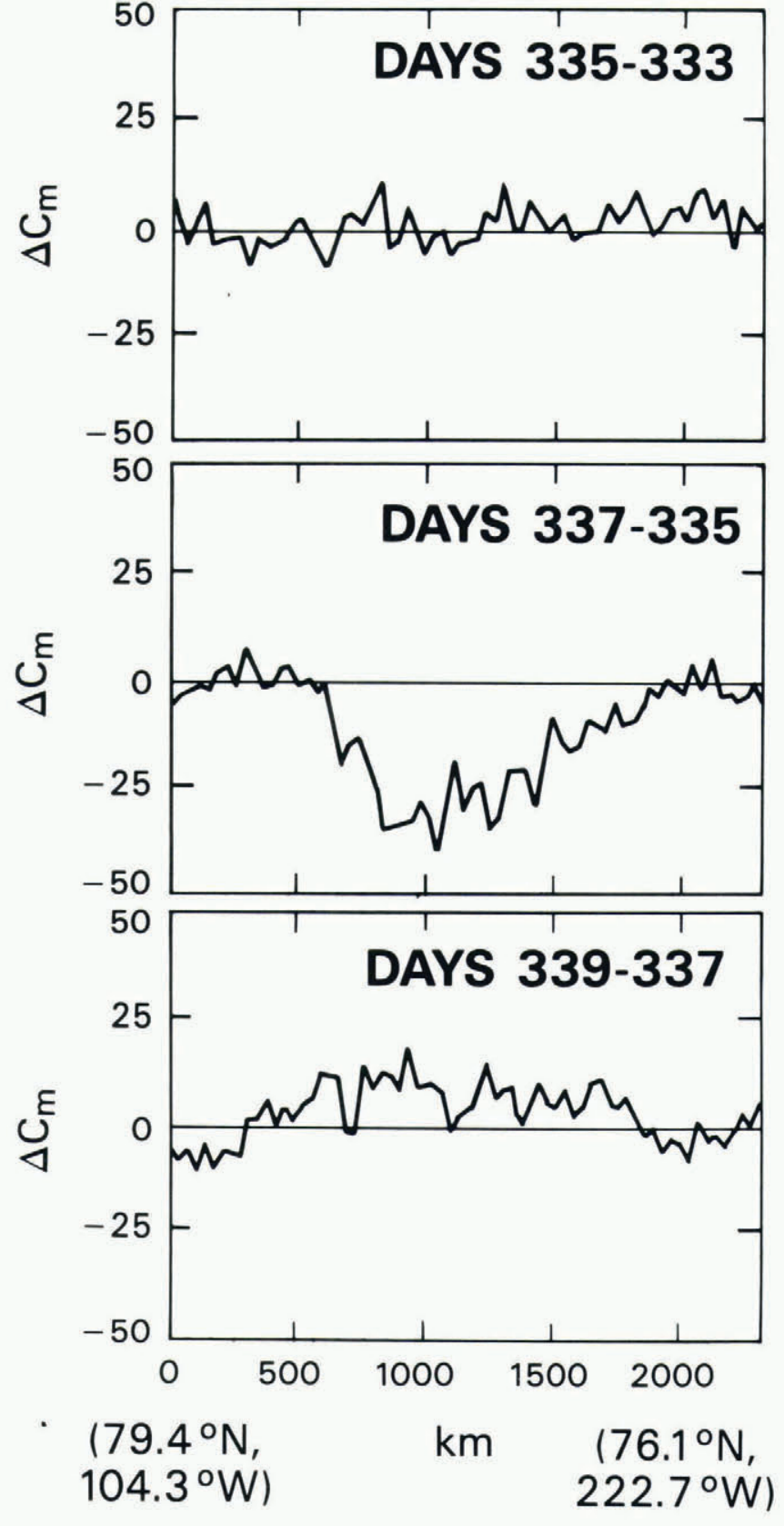

Fig.11. Changes of SMMR multiyear ice concentration along transect from lat. $79.4^{\circ} \mathrm{N}$., long. $104.3^{\circ} \mathrm{W}$. to lat. $76.1^{\circ} \mathrm{N}$., long. $142.3^{\circ} \mathrm{E}$. for three 2 day periods of 1980: $28-30$ November (top), 30 November-2 December (middle), and 2-4 December (bottom).

the large-scale ice mass balance and the associated thermal and salinity fluxes to the atmosphere and ocean.

\section{ACKNOWLEDGEMENTS}

Support for this study was provided by the National Science Foundation, Division of Polar Programs, through grant DPP-8511443 for author J.E.W. and by NASA's Oceanic Processes Program for author H.J.Z. Computerprogramming assistance was provided by Becky Ross, Steve Fiegles, and Scott Bringen.

\section{REFERENCES}

Cavalieri D J, Gloersen P, Campbell W J 1984 Determination of sea ice parameters with the Nimbus 7 SMMR. Journal of Geophysical Research 89(D4): 5355-5369

Hibler W D III 1979 A dynamic thermodynamic sea ice model. Journal of Physical Oceanography 9(4): 815-846 
Hibler W D III 1980 Modeling a variable thickness sea ice cover. Monthly Weather Review 108(12): 1943-1973

Hibler W D III, Ackley S F 1983 Numerical simulation of the Weddell Sea pack ice. Journal of Geophysical Research 88(C5): 2873-2887

Hibler W D III, Walsh J E 1982 On modeling seasonal and interannual fluctuations of Arctic sea ice. Journal of Physical Oceanography 12(12): 1514-1523

Parkinson C L 1983 On the development and cause of the Weddell polynya in a sea ice simulation. Journal of Physical Oceanography 13(3): 501-511

Parkinson C L, Bindschadler R A 1984 Response of Antarctic sea ice to uniform atmospheric temperature increases. In Hansen J E, Takahashi $\mathrm{T}$ (eds) Climate processes and climate sensitivities. Washington, DC, American Geophysical Union: 254-264 (Geophysical Monograph 29; Maurice Ewing Volume 5)

Parkinson C L, Washington W M 1979 A large-scale numerical model of sea ice. Journal of Geophysical Research 84(C1): $311-337$

Thorndike A S, Colony R 1981 Arctic Ocean buoy program, 1 January 1980-31 December 1980. Seattle, University of Washington. Polar Science Center

Thorndike A S, Colony R 1982 Sea ice motion in response to geostrophic winds. Journal of Geophysical Research 87(C8): 5845-5852

Thorndike A S, Rothrock D A, Maykut G A, Colony R 1975 The thickness distribution of sea ice. Journal of Geophysical Research 80(33): 4501-4513

Walsh J E, Hibler W D III, Ross B 1985 Numerical simulation of northern hemisphere sea ice variability, 1951-1980. Journal of Geophysical Research 90(C3): 4847-4865

Williams E, Swithinbank C, Robin G de Q 1975 A submarine sonar study of Arctic pack ice. Journal of Glaciology 15(73): $\quad 349-362$

Zubov N N 1945 L'dy Arktiki, Moscow, Izdatel'stvo Glavsevmorputi [English translation: Arctic ice. San Diego, US Navy Electronics Laboratory, 1963] 